
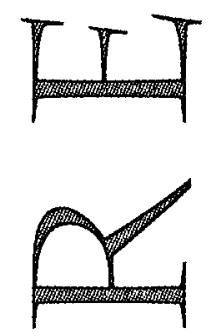

\title{
AMCP Speakers Reinhardt and Satcher Paint Bright Future
}

Even though many challenges face the health care system in the United States, the future looks bright for managed care, and managed care pharmacy in particular. That was among the themes that emerged during presentations delivered at AMCP's Educational Conference in Orlando, which drew almost 1,500 people.
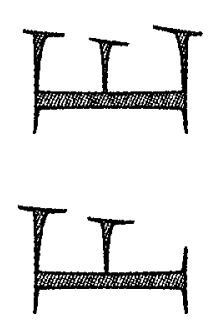

$\mathrm{R}$ enowned Princeton University Prolessor Uwe Reinhardt brandished his dry wit and drew on his experience as a leading health policy analyst to offer his views on managed care and the future direction of health care in this country. He delivered his keynote address on Friday, November 1.

\section{HEALTH CARE: A CRISIS IGNORED}

Politicians paid little if any attention to the issues confronting our health care system during the recent elections. Meanwhile, the number of Americans with no or inadequate health coverage continues to grow. By the end of this century the number of uninsured Americans could reach 60 million, and an additional 20 million to 30 million will have inadequate insurance, Reinhardt said. 
Universal coverage will not happen in this country in the foreseeable future. Insurance reform measures enacted to date also will not solve most of the problems, he said. The Kennedy-Kassebaum law passed last year does "less than meets the eye." Even though government officials have estimated the law could help as many as 25 million Americans keep their health coverage, the reality is that the law simply gives these individuals the right to buy insurance; it doesn't impose limits on what insurers can charge. "So if you are sick, you will not get it [insurance]."

Reinhardt predicted the emergence of a three-tiered health system, with the poor and uninsured getting their care from public clinics and hospitals, the middle classes receiving care through managed care systems, and the wealthy still wedded to traditional fee-for-service systems. The last group stands to benefit most from proposed medical savings accounts. "They make sense for the wellto-do who can afford to pay the first $\$ 4,000$ a year out of their own pockets, especially if that money can be put into a pre-tax income account," Reinhardt said.

The United States has lagged behind other nations in controlling health spending. During the 1980s, Europe began tying health spending as a percentage of the GNP to the growth of the national product. In the U.S., however, rapid inflation continued, prompting analysts to plot graphs showing that if trends stayed the same, the United States would spend on health care an amount equal to $18 \%$ of the GNP by the year $200050 \%$ by 2050 , and $81.5 \%$ by 2100 .

\section{THE QUALITY/QUANTITY DEBATE}

Reinhardt has always disagreed with the theory held by many that the more we spend on health care, the higher the quality of care. "I once even asked an eye doctor, if you are in the middle of an eye operation, and you hear on the radio that the price for cataract surgery is going down from $\$ 2,500$ to $\$ 1,500$, what are you going to do to lower the quality of care? As you stoop over the patient, are you going to flick cigarette ashes in his eyes?" Reinhardt quipped.

Research has shown that up to a point, spending more on health care does improve quality. But beyond that, the benefits of spending more max out, and you can end up doing too many surgeries, over-medicating patients, and keeping people in the hospital too long.

\section{Reinhardt predicted the emer-} gence of a three-tiered health system, with the poor and uninsured getting their care from public clinics and hospitals, the middle classes receiving care through managed care systems, and the wealthy still wedded to traditional feefor-service systems.

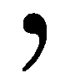

More people gradually are beginning to accept the idea that, by spending less on health care, society can spend more for other socially beneficial commodities, such as education, Reinhardt said. "This idea-that rationing health care is inherently evil-is wrong," Reinhardt said, noting that the media frequently criticizes managed care on that point. But Reinhardt also chided managed care plans that take this idea too far. "The managed care industry does some awfully dumb things, like kicking mothers out of the hospital one day after having a baby," he said. "Part of the problem with the managed care industry is that they sometimes behave like elephants in a porcelain shop, and that, of course, offends a lot of people."

Despite these perceived problems, this movement toward managed care is having tangible, positive effects. Recent data, including that compiled by the employee consulting firm KPMG Peat Marwick, show that health care costs are stabilizing. In 1996, health insurance premiums paid by employers rose at rates below inflation and, while some of that is because of cost-shifting to employees, "there is no question that health care spending has abated" in general.

\section{MANAGED CARE PHARMACY: THE NEXT PHASE OF COST CON- TAINMENT AND QUALITY CONTROL}

Managed care-driven cost abatement has many implications for managed care pharmacy, Reinhardt said. During the first phases of cost-containment efforts in this country, emphasis was placed on reducing hospital stays and getting provider discounts. "The next front to be attacked will be pharmaceutical costs," Reinhardt said, adding that this especially will be true as the population ages, since more individuals will have to rely heavily on the use of medication.

Drug benefit management also makes sense from a quality and outcomes perspective. For decades, few people paid attention to the many druginduced illnesses that occur because drug prescribing was uncoordinated and patients on drugs rarely were monitored. "So I would not be shy about my profession," Reinhardt told the audience. "It's a natural thing to have happened."

Pharmaceutical companies, accustomed to the old ways of doing business, naturally have resisted this emerging 
process, Reinhardt said. Under the old system, wholesalers and manufacturers sold directly to doctors, armed with "drug samples, literature, ballpoint pens, and fluffy animals," he quipped. The new world, however, "is one of megabuyers, such as yourselves, and you have all the ballpoint pens you need."

Use of formularies is simply one component of this new world order. "When you think about it, a formulary is nothing more than selective contracting," he said. If a plan carries only six antibiotics instead of 20 , but gets the same clinical results and saves some money in the process, there should be nothing controversial about it, according to Reinhardt.

\section{FORMULARIES: FOOD FOR THOUGHT}

The study published last year by researcher Susan Horn again has raised negative publicity regarding use of formularies. The Horn sludy did not show a cause-and-effect relationship between formulary use and higher utilization or medical costs, Reinhardt said. "But I would not disregard the study; there is something there," he told AMCP attendees, noting that in some cases, cheaper drugs are not always the best option for patients. AMCP has been highly critical of the Horn study since its publication.

Managed care professionals should consider that many other countries spend more on pharmaceuticals as a percentage of total health care spending than does the United States, he said. Germany, for example, spends one-fifth of its health budget on pharmaceuticals, compared with the $8 \%-9 \%$ the U.S. spends. "The countries that spend a lot on pharmaceuticals actually spend less on health care as a percentage of the GNP than countries that spend less on pharmaceuticals. So there is a lot of research yet to be done in this area."
Managed care organizations that wish to stave off some of the antiformulary sentiment may want to consider adopting a point-of-service reimbursement approach for patients and physicians who opt to use nonformulary products, in which the plan covers a drug entirely if it is on the formulary, but pays half if it is not, Reinhards suggested.

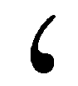

\section{Research has shown that up} to a point, spending more on health care does improve quality. But beyond that, the benefits of spending more max out, and you can end up doing too many surgeries, over-medicating patients, and keeping people in the hospital too long.

\section{，}

Despite its critics, managed care will continue to drive the future direction of health care, both in the United States and abroad, he said. "I think managed care and your piece of it-pharmacy - is the thing of the future," Reinhardt said. "There is a tremendous opportunity to put pharmacists on the map as members of the research team." Reinhardt's closing advice to the audience was this: "Exploit the inevitable."

\section{PUBLIC HEALTH: STILL REACH ING NEW MILESTONES}

David Satcher, M.D., director of the federal Centers for Disease Control and Prevention (CDC) in Atlanta, shared his per- spectives on the role managed care pharmacists can play in promoting public health and invited AMCP to work with the agency on future public health projects. He delivered his keynote on Saturday, November 2.

Efforts at improving public health have been quite successful over the past two decades, David Satcher told AMCP attendees. In 1977, smallpox was eradicated worldwide. In 1991, polio was eliminated from the Western Hemisphere, and it could be eradicated worldwide by the turn of the century. "There is nothing in pharmacy of which we can be prouder than the role immunizations have played in improving the health of children and in preventing diseases in this country and throughout the world," said Satcher.

Eliminating polio not only will ease pain and suffering, but its eradication could save the U.S. roughly $\$ 250 \mathrm{mil}$ lion a year spent on assisting victims overseas and another $\$ 1.5$ billion worldwide, he added.

Satcher outlined several items to keep in focus as public health professionals move into the future:

- "There is no substitute for good rigorous science," whether it is in dealing with an outbreak of the deadly ebola virus in Zaire or in preventing teenagers from taking up smoking. Training programs will continue to be important, such as CDC's Epidemic Intelligence Program. When that program started in 1951 , only physicians were enrolled; today about one-half the students are nonphysician health professionals, inclucling pharmacists and nurses. "We realize you cannot have a successful public health team without that kind of multidisciplinary approach."

- Prevention is the best investment. The U.S. spends \$1. trillion per year on health care, yet only $1 \%$ of that supports

Continued on page 36 
population-based prevention. Like managed care organizations, CDC recognizes the value of good preventive efforts, such as screening and treating chlamydia and pelvic inflammatory disease in women, which can prevent more than 150,000 women from becoming infertile each year.

\section{- Partnerships are important. CDC's} partnering with other groups such as the World Health Organization, UNICEF, and Rotary International was instrumental in eliminating polio. Likewise, CDC two years ago partnered with the YWCA and Avon Products to educate millions of women about the importance of cervical and breast cancer screening

"The parmerships that we have with managed care organizations in this area are important. Together, we can make some tremendous inroads into improving the health of people," Satcher said. Over the past two years, CDC has helped fund managed care programs to look at the efficacy of their approaches to promoting adult and childhood immunizations and tobacco-use cessation. One recent managed care partnership success was the November launch of a pediatric asthma outreach program in Atlanta, in which managed care plans and public health officials will work to reduce the incidence of pediatric asthma emergencies within the inner city population.

- Public health must be global to be successful. Microorganisms, tobacco, and violence spread across boundaries. One of the biggest challenges faced today by public health officials and pharmacists is the growing microorganism resistance to antibiotics. CDC first identified penicilin-resistant strains of bacteria in Asia 20 years ago, before they emerged as a problem in the U.S.

Another CDC analysis has shown that $35 \%$ of pneumonia organisms tested were resistant to penicillin. Challenges ahead will include addressing the inappropriate use and prescribing of antibi- otics and other drugs, including the antiviral drug zidovudine (AZT), "to which we are already seeing resistance."

\section{PHARMACY: KEY TO GOOD PUBLIC HEALTH EFFORTS}

Pharmacy will need to work with medicine and public health officials to effectively meet these new challenges. One challenge $C D C$ faces regularly is surveillance aimed at determining the causes of morbidity and mortality and identifying rișk factors. "I believe that pharmacies are in a very key position to contribute to surveillance and monitoring," Satcher said. He cited this example: In the early 1980s, CDC's pharmaceutical service, which procures and provides drugs for rare diseases, noticed more requests for pentamidine to treat pneumocystis carinii pneumonia in

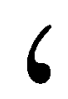

If a plan carries only six antibiotics instead of 20, but gets the same clinical results and saves some money in the process, there should be nothing controversial about it.

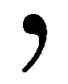

young men from Los Angeles and New York. This eventually led to CDC's identifying the AIDS epidemic in 1981, two years before the HIV virus was discovered. Pharmacists also have been among the first health professionals to identify the incidence of water-borne diseases, such as the one that affected 400,000 people in Milwaukee in 1993, by noticing increased requests from patients for antidiarrheal products

"Pharmacists also are in a position to monitor antibiotic prescriptions and sales patterns, and, in monitoring, 1 think we begin to see how drug resistance develops," Satcher said. "We need to be a team that works together to educate physicians and patients" about appropriate and inappropriate use of these medications, and how inappropriate use "could affect public health for years to come."

"In the managed care environment, especially, pharmacists can perform important health assurance functions," such as reviewing patient records to check their immunization status, reminding parents and physicians about the need to vaccinate children, and reminding the elderly to get influenza and pneumonia vaccines, he said. Currently, only about $30 \%$ of seniors who should be vaccinated against pneumonia are getting their shots, even though Medicare covers this service. "We could save $\$ 1.6$ billion a year if we appropriately implemented the vaccine," Satcher said.

Pharmacisis can play a role in educating AIDS patients and their caregivers about the need to take prophylactic medications for preventing opportunistic infections, again taking into account local patterns of antibiotic resistance when making prescribing decisions, he said. As the most trusted members of the health care team, pharmacists also can educate patients upfront about the risk of HIV; CDC currently is involved in a pilot project in Alabama in which pharmacists are taking a lead role in counseling and educating patients about prevention.

Other opportunities for pharmacists include minimizing drug adverse effects and drug interactions. This will be especially important for AIDS and tuberculosis drugs, which are known to interact.

Satcher invited AMCP leaders to visit CDC facilities and officials in Atlanta to discuss the possibility of working together to educate providers, patients, and the public on issues important to the future of public health. 